Europe's Journal of Psychology, 7(3), pp. 487-50 1

www.ejop.org

\title{
Effects of manipulating optimal challenge in a music intervention program on situational intrinsic motivation among people with intellectual disability
}

\author{
Amanallah Soltani \\ Faculty of Educational Studies, University Putra Malaysia \\ Samsilah Roslan \\ Faculty of Educational Studies, University Putra Malaysia \\ Maria Chong Abdullah \\ Faculty of Educational Studies, University Putra Malaysia
}

Chang Cheong Jan

Faculty of Human Ecology, University Putra Malaysia

\begin{abstract}
Optimal challenge refers to the balance between the challenge level of an activity and the skill level of an individual involved in the activity. A number of intrinsic motivation theories assume that optimal challenge is an influential facilitator of intrinsic motivation. Some researchers attempted to prove this assumption among people without any disability, using problem solving strategies or computer game playing activities. This study was aimed at determining its effectiveness among people with mild or moderate intellectual disability, using a music intervention program with three conditions. The results of one way repeated measure ANOVA and subsequent comparisons in pairs revealed that the high level of situational intrinsic motivation in the first condition of the intervention program where optimal challenges were provided for the first time significantly decreased to a low level in the second condition, where no optimal challenges were provided. It significantly increased again to a high level in the third condition, where optimal challenges were provided for the second time. The findings confirmed the importance of optimal challenge in promoting situational intrinsic motivation, as mentioned by intrinsic motivation theories, among people with intellectual
\end{abstract}


disability in a music intervention program. For implementing guidelines, some practical implications are mentioned.

Keywords: Optimal challenge, situational intrinsic motivation, intellectual disability, music intervention program.

Optimal challenge or, in other words, challenge-skill balance refers to the stability between challenge of an activity and the skill level of an individual involved in the activity. It has been mentioned that optimal challenge is an influential facilitator in promoting intrinsic motivation. In any activity, people are more intrinsically motivated when they are optimally challenged. Tasks which are too easy or too difficult are unable to promote intrinsic motivation. Only tasks that are well within the persons' ability and optimally challenge them could improve intrinsic motivation. Optimal challenge is a concept at the heart of three well-known intrinsic motivation theories, namely self-determination theory, Harter's model of effectance motivation, and theory of flow experience.

Based on self-determination theory (Ryan \& Deci, 2000), intrinsic motivation could be enhanced by a feeling of optimal challenge and competence. In any activity, people feel competent and more self-determined if their skill's level is balanced with the level of challenges. Further, mastery goal orientation, autonomy supportive environment and informative feedback are also important (Mandigo \& Holt, 2000). According to Harter's (1978) model of effectance motivation, optimal challenge is a key concept in promoting effectance motivation. Effectance motivation, a form of intrinsic motivation, refers to the intrinsic pleasure an individual feels from attempting and mastering challenging tasks (White, 1959). Finally, based on the theory of flow experience (Csikszentmihalyi, 1975, 1990) optimal challenge or challenge-skill balance is an important facilitator of flow. Flow experience, associated with forms of intrinsic motivation, is an internal state defined as a condition whereby a person is intensively involved in an activity to the point that he or she becomes unaware of the time spent and the place that he/she is in.

To support intrinsic motivation theories, some researchers have empirically examined the effect of optimal challenge on intrinsic motivation by measuring the amount of time that the participants are involved in the activity during a free choice interval. For instance, Danner and Lonky (1981) divided ninety 4-10 year old children into three groups, based on their cognitive ability levels. The subjects were introduced to three classification tasks which varied in the level of difficulty and then left alone with the tasks. The results showed that children preferred to spend more time on tasks that 
were one step ahead of their cognitive ability level. Mandigo and Holt (2006) also examined the effect of optimal challenge on situational intrinsic motivation in twenty-seven elementary students between the ages of 7-9 years during a physical education class. Participating in semi-structured interviews to describe their experience of the activities, all the participants reported more time spent on the optimally challenging activities. In addition, Liu and Santhanam (2007) conducted a study with 110 business students who participated in online game playing. They also found that when the challenge intensity of the game is moderate, participants played more games for a longer time, but when it is high, participants paid no attention to the game. Furthermore, Sit, Lam, and Mckeniz (2010), observed 60 primary school children during a free choice interval of electronic game playing. During the game, the children had free access to select interactive or sedentary versions of electronic game playing. In addition, during the interactive games they had the free choice to adjust the intensity or challenge of the activity based on their skills' level. The results showed that children spent more than half of their available time participating in interactive game playing, especially when there were opportunities to modify the level of intensity for the tasks.

To examine the impact of optimal challenge on experiencing flow, as a form of situational intrinsic motivation, Rheinberg and Vollmeyer (2003), and Sackett (2008) conducted experimental studies where the difficulty level of computer game was manipulated to determine its effect on experiencing a state of flow. The studies showed that participants demonstrated significantly higher levels of flow experience in conditions during which the levels of task difficulty were moderate in comparison with conditions during which the level of task difficulty was either easy or too difficult. As well, Keller and Bless (2008), conducted an experimental design to test for the causal impact of skill challenge balance on flow experience. The task was a computer game that had different playing modes. The expanded condition was designed to keep challenge at a very low level so that participants were over-skilled for the game. The adaptive condition was designed to create a balance between skill and challenge by automatically adapting the level of difficulty of the game to the individual participants' skill level, thereby making it very challenging. The researchers found that participants in the adaptive condition were more likely to experience flow. The approach of Keller and Bless (2008) in manipulating the level of optimal challenge is superior to previous studies as the participants' individual skilllevel was taken into account, rather than assuming that all participants had approximately the same skills level. It was a situation with real challenge-skill balance in which the challenge level of the activity was balanced with the skill level of the participants individually. 
The studies mentioned above have empirically confirmed the importance of optimal challenge on situational intrinsic motivation using problem solving activities, physical activities, or computer game playing among people without any disability. However, no study was found to support the influential effect of optimal challenge on situational intrinsic motivation among people with intellectual disability.

People with intellectual disability (ID) usually suffer from a variety of physical, cognitive, and learning problems which negatively affect their functional ability (Taylor, Richards, \& Brady, 2005). The low functional abilities of people with ID are usually reflected in their failures, especially when they are involved in some physical, social, or cognitive mastery situations. Experiencing repeated failures in such situations may lead them to feel anxious in new mastery situations (Herter, 1978; Zigler and Bennete-Gate, 1999). A strategy that these people may use to avoid the feeling of anxiety is to escape from mastery situations by being involved in situations that have no challenging outcome (Zigler and Bennett-Gate, 1999). Such situations exist in some vocational training centers and sheltered workshops, where the intellectually disabled participate in routine activities such as sealing envelops, packing, sorting and folding pamphlets. These activities are usually repeated daily and throughout the whole work schedule. Although being involved in such continuous routine activity might prevent people with ID from feeling anxiety, due to lack of optimal challenge, it might also undermine their intrinsic motivation.

The current study was aimed at examining the importance of optimal challenge on situational intrinsic motivation in an individualized music intervention program among people with ID. Some practical implications have been provided for those who plan to facilitate intrinsic motivation among people with ID using special programs such as a music intervention program.

Method

Participants

Thirty participants were randomly selected from a population of 120 adolescents and young adults with mild to moderate ID in two vocational training centers and one sheltered workshop of the Wisma Harapan organization in Malaysia. The participants were 20 males and 10 females aged 15-25. All the participants grew up in their family and communities, attended special primary schools, and had no behavioral problems, paralysis, or deafness. They were always involved in routine 
activities such as sealing envelops, packing, sorting and folding pamphlets through the whole day from 8 am to 4 pm under the supervision of three teachers.

The parents or guardians of the participants signed the informed consent and gave permission for the research project. In addition, a written consent was obtained from the manager of the organization.

Research design

In this study, a one-group within-subject experimental design or, in other words, a one group repeated-measure experimental design, was used to manage the sample size, handle individual teaching process, and remove variance caused by individual differences. To conduct the within-subject experimental design, an individualized music intervention program with three conditions was carried out during a three months period.

Music intervention program used in the study

Due to individual differences in the potential ability of people with ID (Taylor, Richards and Brady, 2005), a continuum of melodies with variety in challenge levels, from very simple to more complex, was used to provide appropriate musical tasks for each participant, based on his/her skills level. The musical tasks were presented to the participants during the music intervention program, using appropriate musical instruments and special teaching strategies.

With respect to the restricted abilities and limitations of people with intellectual disability (Taylor et al., 2005), the special teaching strategies used in the music intervention program were: (a) musical task analysis in which the tasks to be taught were broken down into smaller and sequential units, (b) stating the lesson's goals clearly and providing appropriate feedbacks, (c) repeating materials, skills and concepts several times, (d) speaking in short simple sentences without talking down, (e) performing one musical task rather than multiple tasks, (f) adapting the amount of time allocated for completing a task, and (g) using auditory rote learning or teaching music by ear instead of notation.

With respect to the limitations of the intellectually disabled in their sensory-motor coordination (Taylor et al., 2005), it was necessary to provide a standard and attractive musical instrument with simple physical nature and beautiful sounds. Thus, a xylophone which has these characteristics was selected as the instrument used in the music intervention program. In addition, due to their cognitive, memory and attention problems, the intellectual disabled might be unable to follow the beats 
correctly (beats are some regular pulsations or equal units of time in a rhythmic pattern). Thus, an auto accompaniment system was used to help the participant to follow the beats. Auto accompaniment is a system, a sort of sound mirror, which is able to produce music in the same style as a person playing his or her own instrument.

A small quiet room with appropriate facilities in Wisma Harapan organization center in Malaysia was selected as the experimental room. While all the thirty participants continued to perform their daily activities in the center, they were also invited to the experimental room in person to be involved in a half an hour individualized session twice a week. So each participant had 30 individualized sessions conducted during the three different conditions of the music program.

The first condition of the experiment conducted in the first ten sessions of the program was named as "providing optimal challenge for the first time". Musical tasks were taught to each participant individually by selecting the first simple melody in the continuum of musical tasks. When the participant mastered the first task, the second but more difficult task was taught. This process continued until each participant could improve or master the tasks based on his/her ability. Due to their individual differences, the number of tasks mastered by the participants differed.

The second condition of the experiment, introduced during the following ten sessions of the program was labeled as "providing no optimal challenge". Here the participants were not taught to master any new musical tasks. Instead, they were free to experiment with the tasks that they had already mastered during the first condition, or perform innovative tasks, or do nothing at all. This condition was called "providing no optimal challenge", because the experimenter did not provide any new activities with higher level of difficulty to the participants from the continuum of musical tasks. In other words, no optimal challenges were provided in this second condition.

The third condition of the experiment, imposed during the subsequent ten sessions of the program, was called "providing optimal challenge for the second time". This means that each participant continued to master new musical tasks in the continuum from where he/she stopped in condition one. For example, if one participant had mastered the first three musical tasks during the first condition, now he/she was taught to master new progressive musical tasks higher than the third task. This was known as "providing optimal challenge for the second time" because, for the second time, each participant, based on his/her ability, was involved in some 
unlimited progressive musical tasks which increasingly provided enough challenge as his/her functional ability improved through practice.

The effect of the intervening variables such as feedback, goal orientation, and autonomy (Mandigo \& Holt, 2009) were controlled in all three conditions of the experiment. To control the effect of goal orientation, the strategies introduced by Ames (1992) were used. These strategies were (a) provide self-referenced improvement based on personal goals, (b) reduce opportunity for normative comparison of ability, (c) evaluate participants individually and privately, based on progress and effort, (d) allow flexible time for improvement and maximum time for practice, and (e) encourage participants to be involved in decision making in an authority structure. To control the effect of autonomy, the suggestions by Reeve (2002) were used, namely (a) minimizing any external reward or punishment, (b) providing opportunity for making choice or conveying a sense of choice, and (c) acknowledging participants' positive and negative feelings about their behaviors.

Positive informational feedback about a performer's competence and his/her personal goals was given in all the conditions of the music intervention program. In addition, the direction of musical melodic or rhythmic pattern in a predictable order also provided clear goals for the participants.

Measures

As many people with ID have difficulty with literary skills and with expressing their internal state appropriately, observational strategies, in which the participant's behaviors are observed during activities, were considered to be the best strategy to assess their intrinsic motivation aspects. Thus, a behavioral measure of intrinsic motivation was used to measure the level of situational intrinsic motivation (SIM) in the three conditions of the experiment. It is a measure of intrinsic motivation based on the amount of time the participant spends on the activity without any external rewards or pressure (Guay, Vallerand and Blanchard, 2000). As per this measure, the experimenter declares that the experiment is formally over and presents an excuse to leave the participant alone for a limited period of time (eight minutes). During this period, the behavior of the subject is videotaped secretly. The seconds that the participant spends on the experimental tasks are calculated as his/her level of SIM.

Statistical analysis

Exploratory data analysis was used to find outliers and determine the normal score distributions in all three conditions of the experiment. Descriptive data analysis was 
applied to reveal maximum, minimum, mean, and standard deviations of SIM scores in each condition of the experiment. Finally, one way repeated measure ANOVA and subsequent comparisons in pairs (Field, 2009), as inferential data analysis, were conducted to determine the overall significant differences between the means of SIM scores across three conditions of the experiment and the significant differences between the means of SIM scores in each pair of conditions.

\section{Results}

The results of exploratory data analysis revealed that there were no outliers among the SIM scores in the three conditions of the experiment and the distribution of the scores could be considered normal in all three conditions. The results of descriptive data analysis, one way repeated measure data analysis, and the comparisons in pairs (Field, 2009) are presented in Tables 1-3.

Table 1: Maximum, Minimum, Mean, and Standard Deviation of SIM Scores in the Three Conditions of the Experiment

\begin{tabular}{ccccc}
\hline Variable & Minimum & Maximum & Mean & S.D. \\
\hline SIM 1 & 64.00 & 480.00 & 328.97 & 137.33 \\
SIM 2 & 50.00 & 151.00 & 86.33 & 23.4 \\
SIM 3 & 75.00 & 480.00 & 321.87 & 109.25 \\
\hline
\end{tabular}

As Table 1 shows, the mean of SIM scores in condition one was 328.97 and its standard deviation was 137.33, which indicates a high level of SIM in this condition, where the participants were provided optimal challenge for the first time. The SIM mean scores in condition two, where no optimal challenge were provided, decreased to a low level of 86.33, with a standard deviation of 23.4. However, in condition three, where the participants were provided optimal challenge for the second time, the SIM mean scores increased to a higher level of 321.87, with a standard deviation of 109.25.

Although the results of descriptive data analysis revealed that the levels of situational intrinsic motivation were different in the three conditions of the experiment, they could not determine whether the differences were significant or not. Thus, it was essential to conduct a one way repeated measure ANOVA. However, before that, as in any parametric test, it was necessary to check the assumptions of repeated measure ANOVA used for situational intrinsic motivation. 
The scale measurement of SIM scores was ratio, the sample was randomly selected from the population. The exploratory data analysis of SIM scores revealed that the distribution of these scores follow a normal distribution. Therefore, the first three assumptions of repeated measure ANOVA were met. However, the results of Mauchly's test statistic of SIM scores showed that the assumption of sphericity had been violated, $X^{2}(4)=26.895, p<.05$. It means there was no homogeneity of covariance in SIM scores between pairs of conditions. Thus, it was essential to apply a correction to compensate for the violation of the sphericity assumption.

Looking at the results of Mauchly's test of sphericity, it was observed that the degree of sphericity using Green house-Geisser correction was .606. Since this value was less than .75, based on Leech, Barrett, and Morgan (2007), Greenhouse-Geisser correction was selected as the best choice for adjusting df and reporting $F$ value in repeated measure ANOVA. Thus, repeated measure ANOVA of SIM scores in which the F-value was calculated based on both assuming sphericity and GreenhouseGessier correction was conducted. The results are presented in Table 2.

Table 2: Repeated Measure ANOVA of SIM Scores

\begin{tabular}{lllllll}
\hline Source & & df & $\begin{array}{l}\text { Mean } \\
\text { Square }\end{array}$ & F & sig & $\begin{array}{l}\text { Partial } \\
\text { Eta } \\
\text { Squared }\end{array}$ \\
\hline \multirow{2}{*}{ Condition } & Sphericity Assumed & 2 & 464766 & 99.460 & .000 & .77 \\
& Greenhouse-Gessier & 1.819 & 766335 & 99.460 & .000 & .77 \\
Error & Sphericity Assumed & 87 & 4672.89 & & & \\
& Greenhouse-Gessier & 52.764 & 7704.961 & & & \\
\hline
\end{tabular}

As seen in Table 2, with Greenhouse-Gessier correction to overcome sphericity violation, the results of repeated measure ANOVA indicated that there was an overall significant difference with large effect size (Cohen, 1988) in the SIM scores across the three conditions of the experiment, $F(1.82,52.76)=99.460, p<.001$ eta $^{2}=$. 77. This means the intellectually disabled participants showed significantly different levels of situational intrinsic motivation over time across the three conditions of the experiment. However, these results could not determine which pair of conditions has significant differences. Thus, following repeated measure ANOVA, comparisons in pairs were carried out. However, for comparison of the conditions in pairs, the 
Bonferroni correction (where the alpha level is divided by the number of comparisons, and ensuring that the cumulative Type I error is below .05) was applied to control the error rate in the experiment. The results of this segment of inferential data analysis are presented in Table 3.

Table 3: The Results of Comparisons in Pairs of Conditions

\begin{tabular}{|c|c|c|c|c|}
\hline & Mean Difference & Std.Error & Sig & $r$ \\
\hline $\begin{array}{c}\text { Condition } 1 \\
\text { Vs } \\
\text { Condition } 2\end{array}$ & 242.633 & 25.014 & .000 & .87 \\
\hline $\begin{array}{c}\text { Condition } 2 \\
\text { Vs } \\
\text { Condition } 3\end{array}$ & -235.533 & 19.928 & .000 & .91 \\
\hline $\begin{array}{c}\text { Condition } 1 \\
\text { Vs } \\
\text { Condition } 3\end{array}$ & 7.100 & 14.277 & 1.000 & .09 \\
\hline
\end{tabular}

As can be seen in Table 3, a significant difference with large effect size (Cohen, 1988) was found among the means of SIM scores between conditions one and two, $p<016, r=.87$. The results indicated that the high level of SIM in condition one, where the participant provided optimal challenges for the first time, significantly decreased to a low level in condition two, where no optimal challenges were provided.

In comparing between conditions two and three, a significant difference with large effect size (Cohen, 1988) was found between the mean of SIM scores $p<.016, r=$ 91. The results indicated that low level of SIM in condition two, where the participants were not provided with optimal challenge, significantly increased to a high level in condition three, where the participants were provided with optimal challenge for the second time.

There was no significant difference between the means of SIM scores between condition one and condition three, $p>.008$. In addition, the effect size was .09 which, based on Cohen (1988) is a small effect size. The results indicated that the participants demonstrated high and statistically same level of SIM both in condition 
one, where optimal challenge was provided for the first time, and in condition three, where optimal challenges were provided for the second time.

\section{Discussion}

It is evident from this analysis that the levels of SIM significantly changed across the three conditions of the experiment. While participants showed a high and statistically undifferentiated level of SIM in conditions one and three, where optimal challenge was provided, they demonstrated a significantly lower level of SIM in condition two, where there was no optimal challenge. These findings highlight the importance of optimal challenge in promoting intrinsic motivation, as proposed by most well known intrinsic motivation theories, including self-determination theory (Ryan and Deci, 2000). These findings are also similar to previous research, which emphasized the positive effect of optimal challenge on intrinsic motivation, by measuring the amount of time people spend being engaged in the activity (Sit et al, 2010; Liu et al, 2007; Mandigo and Holt, 2006; Danner and Lonky, 1981). However, unlike the research which confirmed the positive effect of optimal challenge on SIM among people without any disability, the findings of the current study showed this effectiveness for people with ID.

The findings of the current study have some important practical implications for those who plan to facilitate situational intrinsic motivation among people with ID using special programs such as a music intervention program. In such programs, it is necessary to provide successful activities with a balance between challenge of the activity and the skill level of the participant. This means that, unlike people without disability who are able to promote their intrinsic motivation by looking for new challenges (Ryan \& Deci, 2000), people with ID need situations with challenge-skill balance in order to be intrinsically motivated. However, to provide challenge-skill balance for these participants, there are some prerequisite criteria to be met. The first one is preparing a set of tasks with unlimited challenge levels, which include from very simple to more complex tasks. By using such tasks, appropriate levels of challenge are provided for the participants as their skill levels improve through practice. It was revealed that activities such as sealing envelops, packing, sorting, and folding pamphlets, found in some vocational training centers and sheltered workshops for people with ID, do not provide appropriate challenge for the participants to facilitate intrinsic motivation. The latter is present in a situation with a real challenge-skill balance. A situation with real challenge-skill balance is where the challenge level is balanced for each participant individually based on his/her level of skill. This criterion is particularly necessary for people with ID who present a variety 
of individual differences (Taylor et al, 2005). A situation where the same level of challenge is provided for all participants with different skill levels as in group activities cannot provide a real challenge-skill balance. Consequently it might not be able to facilitate intrinsic motivation among the intellectually disabled.

\section{Conclusion}

This is the first study, which empirically investigates the potential effect of manipulating optimal challenge in a music intervention program on SIM among the intellectually disabled. From these findings, it could be concluded that optimal challenge is an influential factor in promoting intrinsic motivation as proposed by past and present theories of intrinsic motivation.

\section{Acknowledgment}

The authors would like to thank Mr Kamaraj, manager, Selangor and Federal Territory Association for the Mentally Handicapped for the support and facilitation during the experiment and data collection.

\section{References}

Ames, C. (1992). Achievement goals and the classroom motivation climate. In Student Perception in the Classroom (pp. 327-348): Hillsdale,NJ:Erlbaum.

Cohen, J. (1988). Statistical power analysis for the behavioral sciences (2 ed.). New York: Academic Press.

Csikszentmihalyi, M. (1975). Beyond boredom and anxiety: The experience of flow in work and games. Sanfrancisco: Jossey-Bass.

Csikszentmihalyi, M. (1990). Flow: The psychology of optimal experience. New York: Harper and Row.

Danner, F. W., \& Lonky, E. (1981). A cognitive-developmental approach to the effects of rewards on intrinsic motivation. Child Development, 52, 1043-1052.

Field, A. (2009). Discovering statistics using SPSS (3 ed.): SAGE Publication Ltd. 
Guay, F., Vallerand, R. J., \& Blanchard, C. (2000). On the assessment of situational intrinsic and extrinsic motivation: the situational motivation scale (SIMS). Journal of Motivation and Emotion, 24(3), 175-213.

Harter, S. (1978). Effectance motivation reconsidered: toward a developmental model. Human Development, 21 (34), 34-64.

Keller, J., \& Bless, H. (2008). Flow and regulatory compatibility: an experimental approach to the flow model of intrinsic motivation. Personality and Social Psychology Bulletin, 34, 196-209.

Leech, N. L., Barrett, K. C., \& Morgan, G. A. (2007). SPSS for intermediate statistics : use and interpretation (3 ed.). New York: Lawrence Erlbaum Associates.

Liu, D., Li, X., \& Santhanam, R. (2007). What makes game players want to play more? A mathematical and behavioral understanding of online game design. Paper presented at the 12th international conference on Human-computer interaction: applications and services.

Mandigo, J. L., \& Holt, N. L. (2006). Elementary students' accounts of optimal challenge in physical education. Physical Educator, Winter.

Mandigo, J. I., \& Holt, N. I. (2009). Putting theory into practice: enhancing motivation through OPTIMAL strategies. Physical and Health Education Academic Journal, 1(1).

Reeve, J. (2002). Self-determination theory applied to educational setting. In Handbook of Self-Determination Research (pp. 183-203): Rochester,NY: University of Rochester Press.

Rheinberg, F., \& Vollmeyer, R. (2003). Flow experience in a computer game under experimentally varied conditions. Zeitscherift Fur Psychologie, 211, 161-170.

Ryan, R., \& Deci, E. L. (2000). Self-determination theory and the facilitation of intrinsic motivation, social development, and well-being. American Psychologist, 55, 68-78.

Sackett, A. L. (2008). Promoting flow: an investigation of the effect of various task condition on flow. State University of New York.

Sit, H. P., Lam, W. K., \& Mckeniz, T. L. (2010). Direct observation of children's preferences and activity levels during interactive and on-line electronic games. Journal of Physical Activity and Health, 7, 484-489. 
Taylor, Richards, S. B., \& Brady, M. P. (2005). Mental retardation: historical perspective, current practice and future directions. Boston: Pearson Allyn and Bacon.

White, R. W. (1959). Motivation reconsidered: the concept of competence. Psychological Review, 66(5), 297-333.

Zigler, E., \& Bennett-Gates, D. (1999). Personality development in individuals with mental retardation: The Press Syndicate of the University of Cambridge.

About the authors:

Amanallah Soltani is a PhD Student in the field of educational psychology in faculty of educational studies, University Putra Malaysia. His bachelor degree is speech therapy and his master degree is education of intellectually disabled children from Allame Tabatabai University, Iran. He has involved in a number of research projects, especially those related to people with intellectual disability.

Assoc. Prof. Dr. Samsilah Roslan received her first degree in Islamic Studies (Syariah) from El-Azhar University, Cairo and Diploma of Education from International Islamic University Malaysia (UIAM). She joined the Faculty of Educational Studies in UPM as a tutor in 1997. She pursued her master study in UPM in the field of Educational Psychology and was upgraded to a Ph.D degree in 2001. Dr. Samsilah has been actively involved in numerous research projects, especially those related to education for children with special needs, including gifted children and children with learning disabilities such as dyslexia and autism. Findings from her studies has been presented in conferences and published in local and international journals. Dr. Samsilah is currently a lecturer at the Faculty of Educational Studies, UPM.

Address for correspondence: Samsilah Roslan, Research Management Centre, Tower II UPM-MTDC Technology Centre, Universiti Putra Malaysia 43400 UPM Serdang, Selangor, Malaysia

Email: samsilah@educ.upm.edu.my

Dr. Maria Chong Abdullah completed his high school at Ave Maria Convent Secondary School, Ipoh. She holds a doctoral degree in educational psychology from University Putra Malaysia (UPM). She has an experience as a secondary school teacher for 14 years, as a lecturer in teacher training institute for 9 years, and as a lecturer in the Faculty of Educational Studies, UPM, since year 2000. Her field of expertise is educational psychology. She also has been teaching courses such as Educational Psychology, Special Education, Child and Adolescence Psychology, Educational Research at 
bachelor level, and courses such as Classroom Interaction, Problem Solving in Education, and Principles of Educational Psychology at master level. Besides teaching, she has also been involved in activities such as writing, and paper presentations at conferences at national and international levels. She has been involved also in voluntary activities in the areas of psychology and gifted children at national level

Dr Chan Cheong Jan holds a Doctor of Literature in Musicology from Osala University, specialising in ethnomusicology and music education. Dr Chan is currently a senior lecturer at the Music Department, Faculty of Human ecology, University Putra Malaysia. His research interest includes the documentation of folk music in Borneo Island and the transmission of folk music in the urban areas in the Peninsula Malaysia. 